\title{
Exploratory Study on Maternal and Child Health Care Facilities in Two Districts of Karnataka State: A Health Systems Research
}

\author{
Harsha Kumar H N ${ }^{1, *}$, Shantaram Baliga B ${ }^{2}$, Pralhad Kushtagi ${ }^{3}$, Nutan Kamath ${ }^{4}$, Suchetha Rao ${ }^{5}$
}

\section{Harsha Kumar $\mathrm{H} \mathrm{N}^{1, *}$, Shantaram Baliga $\mathrm{B}^{2}$, Pralhad Kushtagi ${ }^{3}$, Nutan Kamath ${ }^{4}$, Suchetha Rao ${ }^{5}$}

${ }^{1}$ Former Associate Professor, Department of Community Medicine, Kasturba Medical College, A Constituent of Manipal Academy of Higher Education, Mangaluru - 575001, Karnataka, INDIA.

${ }^{2}$ Professor Emeritus, Department of Pediatrics, Kasturba Medical College, A Constituent of Manipal Academy of Higher Education, Mangaluru- 575001, Karnataka, INDIA.

${ }^{3}$ Professor, Department of Obstetrics and Gynecology, Kasturba Medical College, A Constituent of Manipal Academy of Higher Education, Mangaluru-575001, Karnataka, INDIA. ${ }^{4}$ Professor, Department of Pediatrics, Kasturba Medical College, A Constituent of Manipal Academy of Higher Education, Mangaluru- 575001, Karnataka, INDIA.

${ }^{5}$ Associate Professor, Department of Pediatrics, Kasturba Medical College, A Constituent of Manipal Academy of Higher Education, Mangaluru- 575001, Karnataka, INDIA.

\section{Correspondence}

\section{Dr. Harsha Kumar H N}

Former Associate Professor, Department of Community Medicine, Kasturba Medical College, A Constituent of Manipal Academy of Higher Education, Mangalore- 575001, Karnataka, INDIA.

Email: drhnhk@rediffmail.com

\section{History}

- Submission Date: 04-08-2018

- Revised Date: 07-11-2018

- Accepted Date: 16-11-2018

DOI : 10.5530/ijmedph.2018.4.31

Article Available online

http://www.ijmedph.org/v8/i4

\section{Copyright}

(C) 2018 Phcog.Net. This is an openaccess article distributed under the terms of the Creative Commons Attribution 4.0 International license.

\begin{abstract}
Introduction: Usually Perinatal Mortality Rate [PMR] constitutes a proportion of IMR. But in Karnataka State of India it is almost equal to IMR. A field based study exploring and comparing the Maternal and Child Health Care Facilities in a well-developed district and backward district of Karnataka State would help in understanding the reasons behind this. So, this study was undertaken. Objectives: 1]. To know the infrastructure and facilities that exist for the perinatal care in two districts of Karnataka. 2]. To know the deficiencies in Infrastructure and facilities if any in the 2 districts. Methodology: A Field based study was conducted in 2 districts of Karnataka State. Maternal and Child Health Care Units which met our criteria in Dakshina Kannada and Koppal Districts were included. Checklists were developed to evaluate the facilities present in these health care units. Trained field workers collected the data from the health care facilities of both the districts. The collected data was scrutinized by the investigators. Results are presented as frequencies and proportions in appropriate tables. This being a qualitative data, the implications have been explained. Results: Totally 63 and 65 Health care facilities met the criteria in Dakshina Kannada and Koppal Districts respectively. Dakshina Kannada District showed a predominance of Private Health Care Facilities [52 out of 63]. Koppal District showed a predominance of Public Health Care Facilities [40 out of 65]. The deficiencies in Health care facilities of both the districts increase the chance of Perinatal Deaths. Conclusion: This study helped in understanding the deficiencies in Health Care facilities. But studies exploring the functioning of these facilities and the Health care Personnel would be necessary.

Key words: Perinatal Deaths, Maternal and Child Health Care Facilities, Dakshina Kannada District, Koppal District.
\end{abstract}

\section{INTRODUCTION}

Infant Mortality Rate [IMR] of India has decreased from 114 in the year 1980 to 40 in the year 2013. So has the Perinatal Mortality Rate [PMR] which was 55.7 in the year 1980 to 26 in the year $2013 .{ }^{1}$ The contribution of Perinatal Mortality Rate [PMR] to Infant Mortality Rate [IMR] has varied from $50 \%$ to $60 \%$ during this period of time. ${ }^{1}$ IMR of Karnataka State in India has also decreased from 71 in the year 1980 to 35 in the year $2011 .^{1}$ The PMR has also decreased from 40.2 in the year 1980 to 33.4 in the year 2011. ${ }^{1}$ The contribution of PMR to IMR has varied from $60 \%$ to $70 \%$ during this period of time. Starting from the year 2011 the contribution of PMR to IMR of Karnataka State has increased to almost 95\% to $99 \%$. The IMR of Karnataka State for the years 2011, 2012 and 2013 are 35, 32, 31 respectively. The PMR of Karnataka State for the years 2011, 2012 and 2013 are $33.4,33.5$ and 30 . So we may see that starting from year 2011 the contribution of PMR to IMR of Karnataka State has increased to almost $99 \%{ }^{1}$ From the available data the reasons for this are not clear. Facilities and Infrastructure for maternal care, delivery and neonatal care play an important role in child survival during the perinatal and immediate neonatal period. So, a field based study that explores the Maternal Child Health Care facilities would be helpful. Such a study would help the policy makers understand the situation better.

The Maternal and Child Health Care facilities are not uniformly developed in the State of Karnataka. The northern parts of Karnataka State lag behind the southern parts of Karnataka State. ${ }^{1}$ A field based study that includes Northern and Southern Parts would be helpful to the policy makers as the circumstances and reasons pertaining to Perinatal Death would be different. Koppal District is considered as one of the 5 backward districts of North Karnataka region. ${ }^{2}$ The PMR of this district has been either equal to or higher than that of Karnataka State. The PMR during year 2012 - 2013 was $30 .^{3}$ Dakshina Kannada District is considered as one of the developed district of South Karnataka Region. The PMR of this district was 12.64 during year 2012-2013 which is far below the PMR of Karnataka State. ${ }^{4}$ Considering the PMRs and the
Cite this article : Kumar HHN, Baliga S, Kushtagi P, Kamath N, Rao S. Exploratory study on Maternal and Child Health Care Facilities in two districts of Karnataka State: A Health Systems Research. Int J Med Public Health. 2018;8(4):152-7. 
operational feasibility it was decided to conduct the study in these two district of Karnataka State.

So, this study was conducted with the following objectives: 1]. To know the infrastructure facilities that exist for the perinatal care in two districts of Karnataka. 2]. To know the deficiencies in Infrastructure and facilities if any in the 2 districts.

\section{MATERIALS AND METHODS}

\section{Study Setting}

This field based study was conducted in 2 districts of Karnataka State. Dakshina Kannada District located in the Southern Part of Karnataka State and Koppal District from the northern part of Karnataka State were considered for the study.

Dakshina Kannada District located in the Southern Part of Karnataka State is divided in to 6 Talukas for administrative purpose. It has a total population of $20,80,640$. It has 8 medical colleges, 5 dental colleges, colleges and hospitals that provide alternative medical facilities to the people. It is also the commercial and industrial hub of Karnataka as it is located on the sea coast with a well-developed port. ${ }^{5}$

Koppal District located in the Northern Part of Karnataka State is divided in to 4 Talukas for administrative purpose. It has a total population of $13,80,920$. It has only 1 medical college and people are referred to southern parts for any tertiary health care services. People are dependent on agriculture which does not work out as this is a relatively dry area with poor rainfall. This is one of the backward districts of Karnataka State. ${ }^{2}$

\section{Study Design}

This is a descriptive study done to explore the perinatal care facilities provided in Maternal Child Health care facilities in both the districts of Karnataka State.

\section{Study Units}

The Maternal and Child Health Care Facilities of both the districts. It was decided to include any Health Care Facility which provided anyone of the following services: 1]. Conducting Deliveries. 2]. Cesarean Section Facilities. 3]. Newborn Care Services, Those Health care facilities which did not meet the above criteria were excluded.

\section{Categorization of Study Units}

The Study Units which met the criteria were categorized in to 4 levels based on the criteria given in the Table 1 . These criteria were devised by a combination of Indian Public Health Standards, National neonatology Forum and UNICEF. ${ }^{6-10}$

At each level if the study unit met the criteria as mentioned in Table 1, it was considered adequate otherwise it was considered deficient.

Labour theatre was categorized as Basic, Optimal and Advanced for the purpose of deciding level based on Indian Public Health Standards. ${ }^{6-9}$ The details of the Basic, Optimal and Advanced are as follows:

\section{Basic}

Which had the following facilities: Labour room with essential requirements, Adult resuscitation tray, Fully equipped delivery trolley, IV drip stand and Stethoscope/ Foetoscope/ Foetal Doppler, essential newborn care. Essential newborn care.

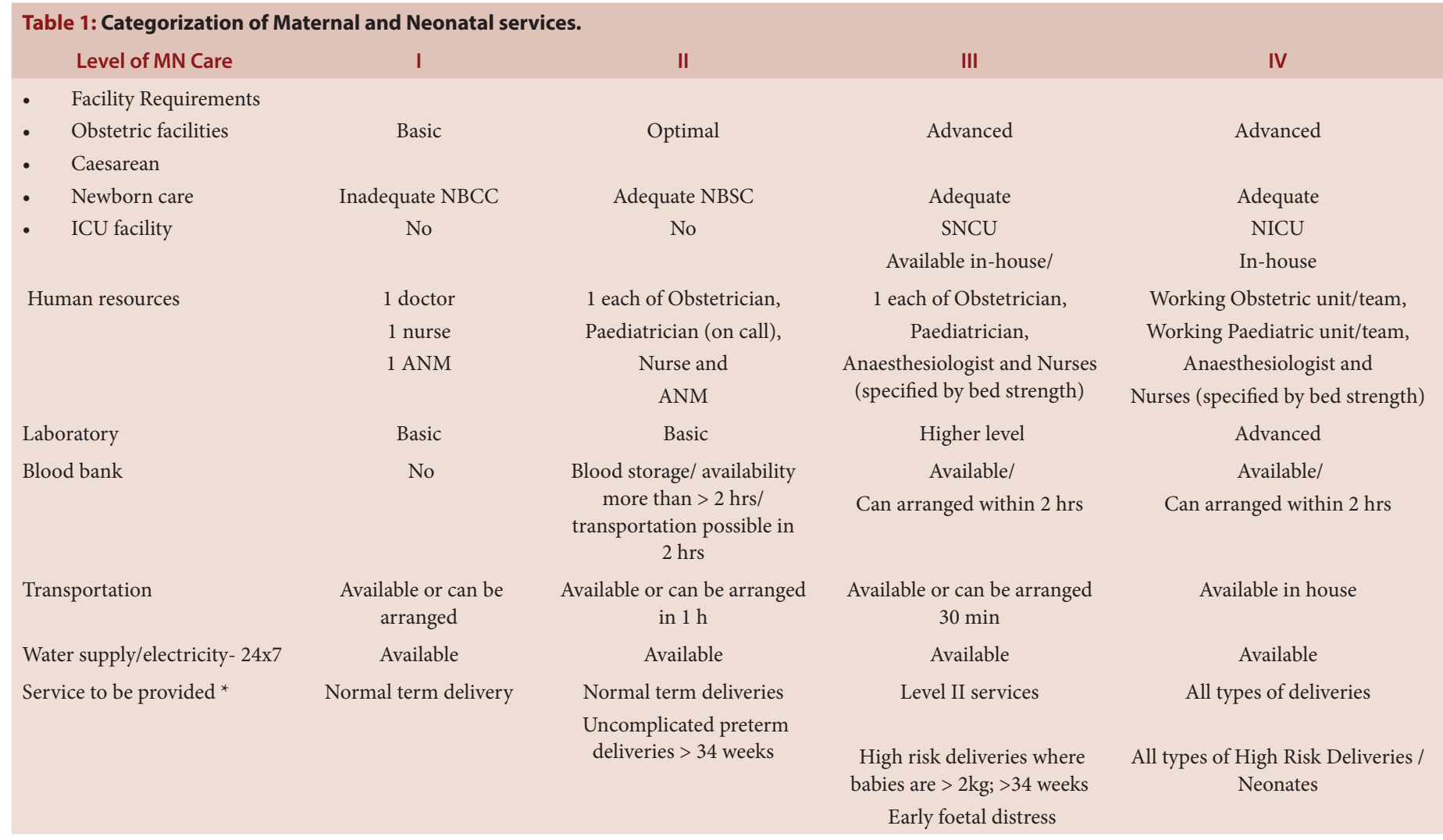

${ }^{*}$ In general the type of deliveries conducted in the facility is based on the available infrastucture in the facility. Level I can provide care for normal term cases to Level IV can provide care for all high risk cases 


\section{Optimal}

Which had the following facilities: Basic facilities, Obstetric forceps/ vacuum, ultrasound scanning, Facility to conduct Caesarean Section Facilities for neonatal resuscitation.

\section{Advanced}

Which had the following facilities: Basic + Optimal facilities, Doppler ultrasound scanning facilities, Continuous Intra-partum foetal monitoring facility - CTG, Facilities to provide, facilities to provide care for high risk newborn.

\section{Study Tools}

Checklists were developed for the purpose of evaluating the facilities present in the Health Care Units that were included in the study. They were Checklists for evaluating 1]. Labour Theatres. 2]. Facilities for conducting a Caesarean section. 3]. Facilities for providing Essential newborn care. 4]. Facilities to care for "High Risk new born".

\section{Pretesting}

The study instruments were Pre-Tested in neighbouring district of Udupi to know the feasibility and appropriateness of use. Some modifications were made in the study instruments to suit our study.

\section{Data Collection}

Permissions were obtained from Karnataka Government to conduct the study. The district Commissioners were directed by the government about the study. Trained Field workers collected the data by visiting the health care facilities. They filled the checklists by observing the equipments in the health care facilities. The doctors in these facilities were approached for any clarifications about the equipments and facilities. The filled checklists were scrutinized by the investigators. In case of doubts the health care facilities were approached more than once to collect the data.

\section{Data Analysis}

The collected data was entered in MS Excel worksheet. It was analysed using SPSS version 12. The results are expressed as proportions in appropriate tables and figures. Comparisons were made between the two districts. The deficiencies in facilities are qualitative data. So, the implications have been explained in sentences.

\section{RESULTS}

Totally 63 and 65 Health care facilities met the criteria in Dakshina Kannada and Koppal Districts respectively. Dakshina Kannada District showed a predominance of Private Health Care Facilities [52 out of 63]. Koppal District showed a predominance of Public Health Care Facilities [40 out of 65]. The geographic distribution of these facilities in both the districts are presented in Figure 1 and 2.

The distribution of these according to level of care is provided in Table 2. It shows a predominance of Level 1 and 2 Public Health Care facilities in Koppal District which are deficient. Most of the level 4 Private health care facilities in Dakshina Kannada district are deficient.

The Maternal and Child Health Care facilities available in these hospitals are presented in Table 3. The number of SNCU, NICU and Warmer Beds in Dakshina Kannada district makes it better placed to handle sick and High Risk Newborns as compared to Koppal District. To fulfil the objective of our study the deficiencies in the health care facilities in both the districts are presented in Table 4. These show that the facilities are deficient in both the districts though Dakshina Kannada District fares better than Koppal District.

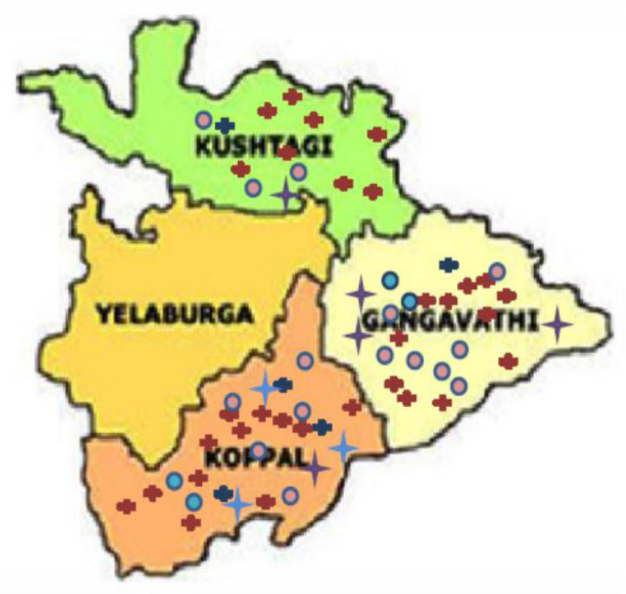

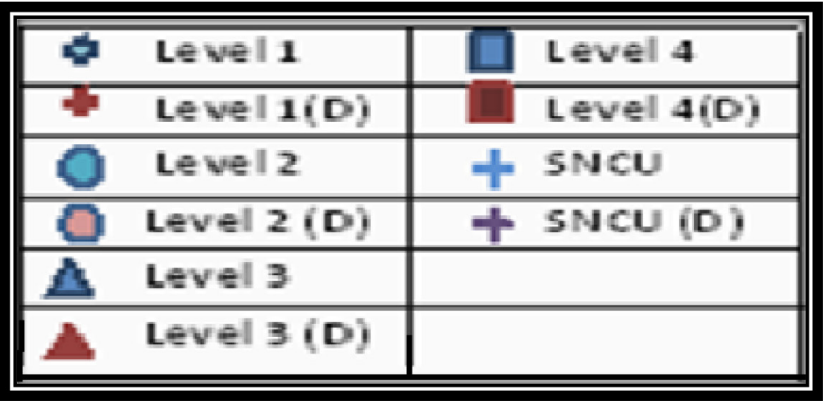

Figure 1: Geographical Distribution of Maternal and Child Health Care Facilities in Koppal District.
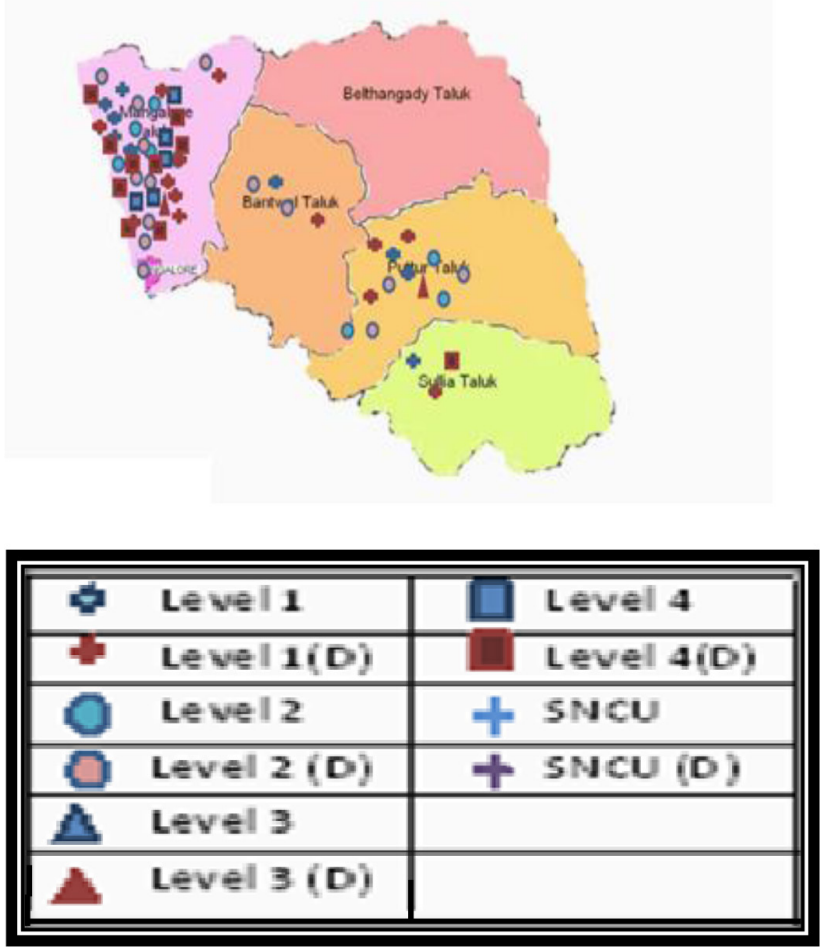

Figure 2: Geographical Distribution of Maternal and Child Health Care Facilities in Dakshina Kannada District. 


\begin{tabular}{|c|c|c|c|c|c|c|c|c|c|}
\hline \multirow[t]{3}{*}{$\begin{array}{l}\text { Level of Maternal/neonatal } \\
\text { care }\end{array}$} & \multicolumn{2}{|c|}{$\begin{array}{l}\text { Dakshina Kannada } \\
\text { Public [ } N=11]\end{array}$} & \multicolumn{2}{|c|}{$\begin{array}{c}\text { Dakshina Kannada } \\
\text { Private [ } \mathrm{N}=52 \text { ] }\end{array}$} & \multicolumn{2}{|c|}{ Koppal } & \multicolumn{2}{|c|}{ Koppal } & \multirow{3}{*}{ Total } \\
\hline & \multirow[b]{2}{*}{$A^{*}$} & \multirow[b]{2}{*}{$D^{*}$} & \multirow[b]{2}{*}{$A^{*}$} & \multirow[b]{2}{*}{$D^{*}$} & \multicolumn{2}{|c|}{ Public [N=40] } & \multicolumn{2}{|c|}{ Private $[\mathrm{N}=25]$} & \\
\hline & & & & & $A^{*}$ & $D^{*}$ & $A^{*}$ & $\mathrm{D}^{*}$ & \\
\hline I & 5 & 4 & 6 & 10 & 5 & 31 & Nil & Nil & 61 \\
\hline II & Nil & Nil & 7 & 15 & 1 & 3 & 2 & 16 & 44 \\
\hline III & Nil & Nil & Nil & 2 & Nil & Nil & Nil & Nil & 2 \\
\hline IV & Nil & 1 & 5 & 7 & Nil & Nil & Nil & Nil & 13 \\
\hline NICU (Paediatric hospitals) ${ }^{* \star}$ & 1 & Nil & Nil & Nil & Nil & Nil & Nil & Nil & 1 \\
\hline SNCU (Paediatric hospitals) ${ }^{* *}$ & Nil & Nil & Nil & Nil & Nil & Nil & 3 & 4 & 7 \\
\hline Total & 6 & 5 & 18 & 34 & 6 & 34 & 5 & 20 & 128 \\
\hline
\end{tabular}

${ }^{*} \mathbf{A}=$ Adequate; $\mathbf{D}=$ Deficiency. At each level if the study unit met the criteria as mentioned in Table no 1, it was considered adequate otherwise it was considered deficient.

**Those paediatric hospitals where maternal care is not given has been placed as NICU/SNCU separately

\begin{tabular}{|c|c|c|c|c|}
\hline \multirow[b]{2}{*}{ Parameter } & \multicolumn{2}{|c|}{ Dakshina Kannada } & \multicolumn{2}{|c|}{ Koppal } \\
\hline & Public (Name of the Place) & Private (Name of the Place) & Public (Name of the Place) & Private (Name of the Place) \\
\hline Number of NBCC & 6 & 41 & 35 & 13 \\
\hline Number of NBSC & 4 & 35 & 3 & 13 \\
\hline Number of SNCU & 1 & 21 & 1 & 7 \\
\hline Number of NICU & 1 & 12 & 0 & 0 \\
\hline \multicolumn{5}{|l|}{ Number of caesarean facilities } \\
\hline Talukal & 0 (Bantwal) & 3(Bantwal) & $1(\mathrm{KPL})$ & 7 (KPL) \\
\hline Taluka2 & 2 (Mangalore) ${ }^{*}$ & 31(Mangalore) ${ }^{*}$ & 1(Gangavathi) & 10 (Gangavathi) \\
\hline Taluka3 & 1(Puttur) & 8 (Puttur) & 1(Kushtagi) & 2 (Kushtagi) \\
\hline Taluka4 & 1(Sullia) & 3(Sullia) & & \\
\hline Number of warmer beds & 43 & 258 & 35 & 14 \\
\hline $\begin{array}{l}\text { Number Neonatal ventilators } \\
\text { (in total) }\end{array}$ & 10 & 32 & 0 & 0 \\
\hline
\end{tabular}

*At the time of conducting the study, Mangalore Taluka was one Taluka. As of now it is divided in to 2 Talukas ie, Mangalore Taluka \& Moodabidri Taluka

\section{DISCUSSION}

This unique type of study conducted in the state of Karnataka has the following implications:

\section{Type of Service}

Table 1 shows that Private Sector is the predominant service provider in Dakshina Kannada but not in Koppal District where Government Sector is the predominant service provider. Available data from National Family Health Survey 4 shows that in the district of Dakshina Kannada, only $38.6 \%$ of total births occur in Public Health Facility. ${ }^{11-12}$ Private sector thrives on the paying capacity of the people. Dakshina Kannada District being a economic and industrial hub with higher per capita incomes implies that more people would pay for better services in the private sector as compared with public sector. Data from NFHS 4 indicate that in Koppal District $72.6 \%$ of births occur in Public Health Care facilities. ${ }^{13}$ Koppal District being a dry and famine stricken area, has more number of people depending upon the public health care facility where the services are free. So, we get to see predominance of private sector in Dakshina Kannada District as compared with Koppal District. This implies that to reduce the PMR in Koppal district, the facilities in government sector needs to be upgraded.

\section{Level of Care}

There is predominance of Level I and II care facilities in Koppal District. There are no Level IV care facilities in Koppal District. Level III and IV care facilities are required for handling High Risk Pregnant women and High Risk Newborns. So, the chances of neonatal and perinatal deaths increase as reflected by the high PMR of Koppal district. Absence of facilities implies that such high risk cases have to be referred to other well developed districts where Level III and IV facilities exist. In Dakshina there are 13 Level IV Facilities. The presence implies that high risk pregnant women and high risk newborns could be cared for in Dakshina Kannada. This is reflected by the low PMR of Dakshina Kannada District.

\section{Deficiencies in Facilities}

Table 4 shows that available facilities do have deficiencies in equipments and facilities. The facilities are better in Dakshina Kannada as compared with Koppal District. High Risk Pregnant women and Newborns could be managed in Dakshina Kannada District. Because of absence of such facilities in Koppal District, service delivery gets affected. This increases 
Table 4: Deficiencies in facilities and equipments of both the districts.

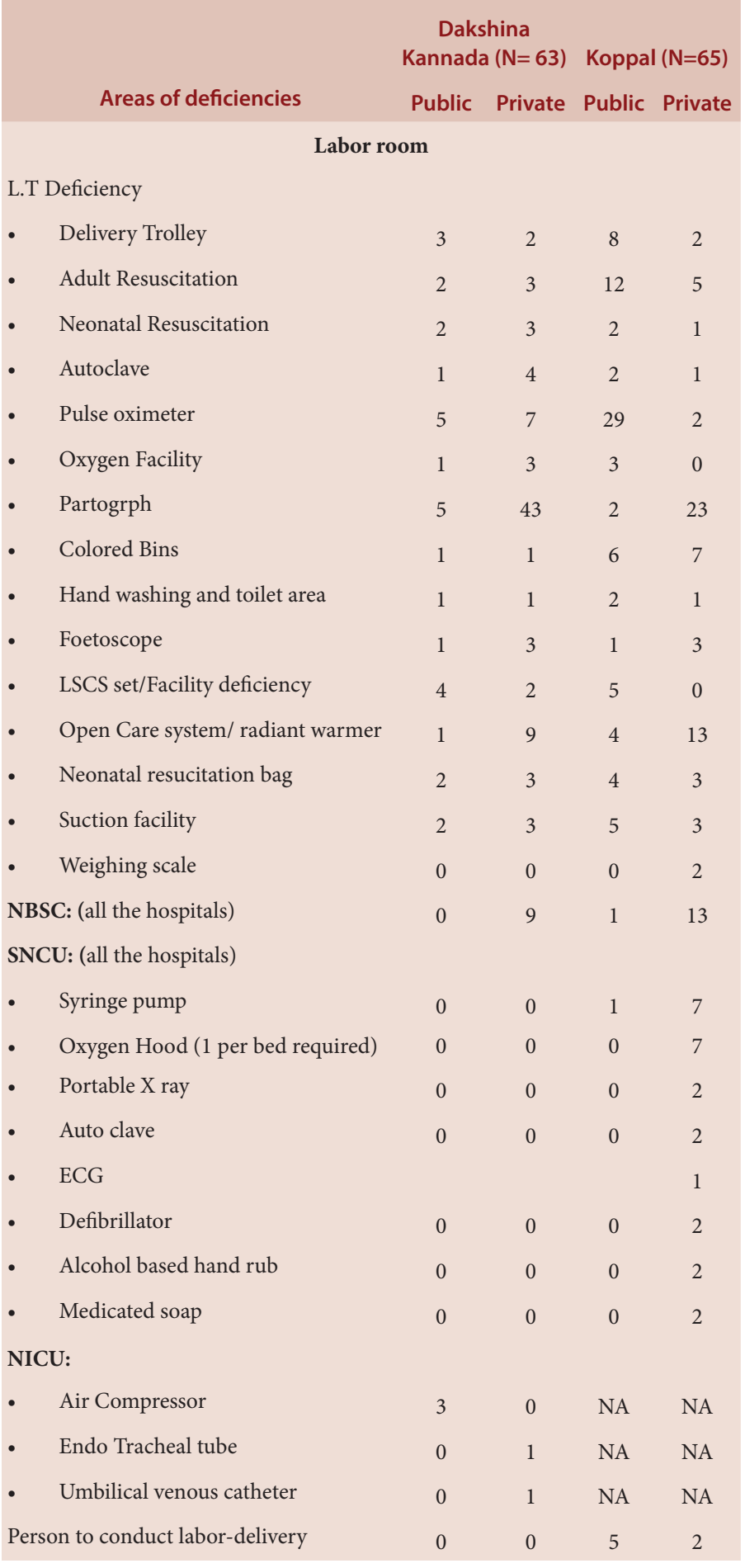

the chances of Neonatal and Perinatal Deaths. So, we get to see the higher PMR in Koppal District as compared with the Dakshina Kannada District.

This study is limited by the fact that due to feasibility reasons we could not study the Functioning of 1]. Health Care facilities. 2]. Health Care personnel involved in providing Maternal and Child health care services in both the districts. Our effort was limited to studying the distribution and availability of infrastructure and facilities.

\section{CONCLUSION}

This study has helped in understanding the type of maternal and child health care facilities in 2 different types of districts of Karnataka State. The comparison of a well-developed district with a backward district of Karnataka State has brought out the type of differences that exist. The existing deficiencies which increase the chances of Perinatal Deaths are also clear. A detailed study to know the functioning of the health care facilities and personnel involved in providing maternal and child health care services of both districts would help in understanding other causes / reasons that would increase the chance of PMR.

\section{ACKNOWLEDGEMENT}

We thank all the hospitals in both the districts for having permitted us to study their infrastructure and equipments. We also thank the government of Karnataka for having given us the permission to visit and document the facilities and equipments in government hospitals of both the districts.

\section{CONFLICT OF INTEREST}

The authors declare no conflict of interest.

\section{ABBREVIATIONS}

PMR: Perinatal Mortality Rate; IMR: Infant Mortality Rate; NICU: Neonatal Intensive Care Unit; SNCU: Sick Newborn Care Unit; NBCC: Newborn Care Corner; NBSC: Newborn Stabilization Corner.

\section{SUMMARY}

An exploratory study was done to know the type of maternal \& child health care facilities in 2 different types of districts of Karnataka State. There are deficiencies in the facilities which increase the chances of perinatal death. A detailed study to know the functioning of the health care facilities \& personnel involved in providing maternal and child health care services of both districts would help in understanding other causes / reasons that would increase the chance of PMR.

\section{SOURCE OF FUNDING}

Funding is by Department of Health Research, Ministry of Health Family Welfare, Government of India, Reference Number: DHR/GIA/35/2014.

\section{REFERENCES}

1. Registrar General of India. Sample registration system (SRS) statistical report 2013, New Delhi. Available from the URL [Accessed on 2 August 2018]: http:// www.censusindia.gov.in/vital_statistics/Compendium/Srs_data.html

2. Registrar General of India. Census of India 2011: District Census Handbook Koppal. Directorate of Census Operations, Karnataka. Available from the URL [Accessed on 2 August 2018]: http://www.censusindia.gov.in/2011census/ dchb/2906_PART_A_DCHB_KOPPAL.pdf

3. National Health System Resource Centre, National Rural Health Mission, Ministry of Health and Family Welfare, Government of India. HMIS Analysis of Koppal District, Karnataka State 2012- 2013:18

4. National Health System Resource Centre, National Rural Health Mission, Ministry of Health and Family Welfare, Government of India. HMIS Analysis of Dakshina Kannada District, Karnataka State 2012 - 2013:18.

5. Registrar General of India. Census of India 2011: District Census Handbook Dakshina Kannada. Directorate of Census Operations, Karnataka. Available from the URL [Accessed on 2 August 2018]: http://www.censusindia.gov. in/2011census/dchb/2921_PART_A_DCHB_DAKSHINA\%20KANNADA.pdf

6. Directorate General of Health Services. Ministry of Health and Family Welfare. Government of India. Indian Public Health Standards (IPHS): Guidelines for Community Health Centre Revised 2012. Available from the following URL [Accessed on 3 August 2018]: http://www.nhm.gov.in/images/pdf/guidelines/ iphs/iphs-revised-guidlines-2012/community-health-centres.pdf

7. Directorate General of Health Services. Ministry of Health and Family Welfare. 
Government of India. Indian Public Health Standards (IPHS): Guidelines for Primary Health Centre Revised 2012. Available from the following URL [Accessed on 3 August 2018]: http://www.nhm.gov.in/images/pdf/guidelines/iphs/iphsrevised-guidlines-2012/primay-health-centres.pdf

8. Directorate General of Health Services. Ministry of Health and Family Welfare. Government of India. Indian Public Health Standards (IPHS): Guidelines for Sub-District / Divisional Hospital Revised 2012. Available from the following URL [Accessed on 3 August 2018]: http://www.nhm.gov.in/images/pdf/guidelines/iphs/iphs-revised-guidlines-2012/sub-district-sub-divisional-hospital.pdf

9. Directorate General of Health Services. Ministry of Health and Family Welfare. Government of India. Indian Public Health Standards (IPHS): Guidelines for SubDistrict / Divisional Hospital Revised 2012. Available from the following URL [Accessed on 3 August 2018]: http://www.nhm.gov.in/images/pdf/guidelines/ iphs/iphs-revised-guidlines-2012/district-hospital.pdf

10. National neonatology Forum, UNICEF. Accreditation Guidelines Level III 2016.
Available from the following URL [Accessed on 3August 2018]: http://www.nnfi. org/att/quick-menu/accreditation-form-of-level-iii-a/1524118114.pdf

11. National Family Health Survey, International Institute of Population Sciences, Mumbai. National Family Health Survey 4: District Fact Sheet. Available from the following URL [Accessed on 3 August 2018]: http://rchiips.org/NFHS/ districtfactsheet_NFHS-4.shtml

12. National Family Health Survey, International Institute of Population Sciences, Mumbai. National Family Health Survey 4: Dakshina Kannada District Fact Sheet. Available from the following URL [Accessed on 3 August 2018]: http:// rchiips.org/NFHS/FCTS/KA/KA_FactSheet_575_Dakshina\%20Kannada.pdf

13. National Family Health Survey, International Institute of Population Sciences, Mumbai. National Family Health Survey 4: Koppal District Fact Sheet. Available from the following URL [Accessed on 3 August 2018]:http://rchiips.org/NFHS/ FCTS/KA/KA_FactSheet_560_Koppal.pdf

Cite this article : Kumar HHN, Baliga S, Kushtagi P, Kamath N, Rao S. Exploratory study on Maternal and Child Health Care Facilities in two districts of Karnataka State: A Health Systems Research. Int J Med Public Health. 2018;8(4):152-7. 